\title{
New contexts, new challenges: revisiting equal opportunities, particularism, and ethnic relations
}

\author{
Malcolm Harrison* \\ School of Sociology and Social Policy, University of Leeds
}

\begin{abstract}
This 'debate piece' discusses issues of equality and diversity in a period of changed circumstances and emergent challenges. The first part notes shifts affecting equal opportunities, the accommodation of 'difference', and the position of low-income groups, and reflects on implications. The second reviews issues around labour market migration and social rented housing. The third comments on the rise of particularism. Finally, the closing section refers briefly to a policy path creating space for localised autonomy and 'consumer insulation' via social housing. This highlights the potential clash with equal opportunities that is implicit within particularism as manifested in the idea of localism. Underpinning the commentary throughout the paper is a view that certain assumptions and apparent certainties in equal opportunities and ethnic relations scholarship appear less reliable than previously.
\end{abstract}

Keywords: equality, policies, ethnicity, housing.

\section{Introduction}

This debate piece revisits equal opportunities, difference and particularism in the light of contemporary complexities, and explores some issues for UK ethnic relations scholarship and research. There is no rejection here of the empirical tradition that charted discrimination over many years, of efforts made in past decades to respond positively to immigration and the needs of minorities, or of the salience of further investigation. Rather, the paper points towards adjustments in perspective. Key themes are that methodologies merit re-appraisal, that more attention should be paid to class and the material base for tensions over in-migration, and that particularisms and their legitimation via multi-culturalism deserve more critical scrutiny. In concluding, the paper proposes local collective rights over assets as a means of assisting settled low-income groups (via 'consumer insulation'), but acknowledges that 
fuller recognition of such rights could raise hard questions about differentiation, and exclusion of 'newcomers'.

To provide links to ongoing events and debates, The Guardian is used alongside academic sources (although limitations of press reporting are understood).

\section{Changed national contexts and some implications}

Cumulative developments in law and regulation from the 1960s onwards have transformed many behaviours and practices, particularly within organisations. Alongside broader socio-economic changes, regulation helped bring about a substantial lessening of overt negative discrimination, and growing public recognition of 'difference' and diversity. Through the 1980 s and 1990s, the UK saw an equality and diversity agenda increasingly brought to bear (Harrison, et al., 2005: 47-66). Changes in regulatory systems and practitioner expectations have been especially important in the public and voluntary sectors, and here the UK built up amongst the most developed approaches in Europe for responding to difference (for summary see Harrison, 2009: 70-76). At least, this seems the case for ethnicity and housing (Harrison, Law and Phillips, 2005).

Nonetheless, problems persist on several equality fronts, perhaps most significantly around racist harassment, under-regulated private firms, specific impairments, newer migrants, sexual orientation, and travellers. Sectoral weaknesses remain, the criminal justice system and associated institutions (for instance) having many problems. Although readers may think first of racism here, less well explored difficulties affect disabled people or those experiencing addiction or other vulnerabilities (for a disability instance see The Guardian, 20 ${ }^{\text {th }}$ May 2009). The tip of a large iceberg became visible under New Labour in the apparently punitive handling of anti-social behaviour concerns related to some disabled or vulnerable people (Harrison and Sanders, 2006).

Housing, however, provides fairly positive illustrations. Some decades ago, 'classic' council housing studies revealed racist discrimination clearly, while negative responses to single parents were also widely known. Overt practices against settled minority groups would be harder to find today, and the position on single parents has shifted. Although potential tenants (white and BME) often face acute shortages of good housing, BME households have moved into social renting in increased numbers. Difficult estates remain a prospect for many tenants, while racist hostilities inhibit choices of localities for BME families, yet many BME groups seem 'already overrepresented in social rented housing', while 'recent statistical evidence suggests that even those groups that have been traditionally under-represented in this sector are now entering it in growing numbers' (Markkanen, 2009: 6). Introduction of 'choice-based lettings' systems, furthermore, may have offered prospects for some reduction in spatial concentration of BME lettings, albeit with implications for risks of potential racist violence outside areas of concentration (Law, 2007: 4). In any event, there seems to have been convergence with white populations in the impact of 'need variables' on tenure, not least those aligned with socio-economic position (and social class), but also those linked to gender. A class gradient occurs within as well as between groups, and is probably increasingly reflected in tenure patterns (albeit that owner-occupation contains numerous low-income households). Ethnic residential 
separation from white groups has been modified by access into larger segments of social renting as well as BME middle-class success in owner-occupation, even though shortage of affordable stock and other variables (such as recent arrival in the UK) complicate outcomes. There are also growing impacts from formation of mixed heritage households and changing composition of white populations, affecting housing alongside other domains, and complicating potential measurement of ethnic differentiation.

The picture of change may be different for BME households as regards urban renewal. Here, older neighbourhoods have suffered from lack of effective national policies to sustain 'downmarket' owner-occupation, while recent direct regeneration interventions (via 'pathfinder' programmes), have raised questions about potential losers amongst low-income households. Even in these fields, however, we might anticipate some similarities across BME and white households in the patterning of consequences, perhaps linked to class, age or gender.

Regarding more general trends, three additional points arise. First, moving into a diversity agenda greatly complicated matters, with needs sometimes seeming increasingly fragmented. Second, no adequate recipe emerged for incorporating claims of religious and cultural groups into public life whilst simultaneously deciding limits on positive responses to multi-culturalism and cultural preference (cf Harrison, et al., 2005: 203-205). Elements in official community cohesion ideas (from 2001 onwards) demonstrated a potential for casting certain categorised instances of cultural difference and ethnic clustering as negative factors (see Flint and Robinson, 2008, for issues). Yet governmental policy - pointing in a different direction - also used multiculturalism as one springboard for a contentious extension of religious control over previously public resources in education (see below).

Third, hierarchies of status and opportunities have become more complex (and less certain, consistent or universalised), with patterns of incorporation by institutions harder to predict or describe. Influential factors include women's successes in education and employment, positive achievements of growing numbers of middle class BME households, and variations by locality, sector, cultural group, cohort and age. Perhaps rather complicated hierarchies now operate within organisational responses to difference, varying over contexts, with some groups (such as people with particular impairments) subject to considerably greater negative discrimination in recruitment, promotion or services than others. Given concerns about inequalities, there has been continuing official pressure to assist prioritised groups, extending into expectations of a search for positive opportunities in specific contexts (see for instance ECU, 2007: 7) Some data sets, however, reveal patterns of statistical representation unlikely in earlier decades. For higher education, the National Audit Office notes that the participation rate for men is 'currently 10 percentage points below that for women', while 'those from non-white ethnic groups are better represented than white people' (NAO, 2008, Summary: 6). White people 'from lower socio-economic backgrounds, both men and women' apparently constitute 'the most under-represented group'.

The changes noted so far have implications for methods and interpretations. More attention needs paying to the array of 'intervening' or 'confounding' variables associated with trajectories for individuals or groups, since these make causation in processes harder to pin down (and comparison less straightforward). It is difficult today to deduce institutional processes or identify their foundations from 'outputs data' on 
categories of people, and statistical representation as a policy target in its own right deserves caution, and selectivity of application. Furthermore, groups themselves can be difficult to delineate meaningfully, and broad comparators such as 'white men' or 'white households' have limited usefulness (and should be disaggregated more often and more effectively). Circumspection should also apply when using measurements of people's feelings of hurt or discrimination. Such data are inadequate to support claims about discriminatory patterns or processes. Informants may attribute unverifiable motivations to other people in complex settings, while depth and character of experience or feelings cannot be standardised for within or between sampled groups, or over time. More generally, increased care is needed before applying grand theoretically-determined templates derived from anti-racist standpoints to particular institutional contexts or the roles of specific groups. Even the theme of 'ethnic penalties' seems less helpful than previously (cf Harrison, et al., 2005). Ways forward include intensive investigations of mechanisms and policy effects, with greater acknowledgement of confounding variables and structural influences, better understanding of human actors, and recognition of domain specificity.

\section{Monitoring economic liberalism and social regulation}

We turn briefly now to economic liberalism and social control, the underlying theme being that more attention should be paid to 'class' and to social regulation. For some time, class and structural factors seemed under-valued, but they appear to have been moving up the agenda in policy debate and analysis. Indeed, one recent press commentary refers to planned legislation on equality as a 'frank recognition of the role of class in Britain', and commends the aim of obliging the 'entire public realm to focus on reducing class inequality' (Toynbee, 2009). Certainly, there is acknowledgement across parts of mainstream media as well as academic and pressure group circles that Britain has become more unequal, that drivers include weak income growth for the low paid and eroded value of state benefits, and that there are serious issues around factors such as the 'poverty of place', a 'two-speed economy', and segregation by wealth and income (for illustrative foci see The Guardian, 8 May 2009; Fitzpatrick, 2005; Minton, 2007). Whether or not proposed legislation brings any profound changes, effective scholarship linking difference and disadvantage must tackle the deep entanglements with socio-economic positions. Topics relevant to housing pathways and neighbourhood life include: cycles of transmitted advantage and how these work; uneven development; households' access to capital and the capacity to plan; opportunities to control one's trajectory and environments longer-term; and intraclass divisions related to place, employment sectors, services and other factors. On the theory front, a key task remains to place individual facets of 'difference' (such as ethnicity or gender), within broader explanatory models encompassing adequate acknowledgement of how systematic inequalities and institutional practices develop over time (cf Harrison with Davis, 2001).

One practical need is to monitor effects of economic liberalism for low-income and vulnerable groups. Although policies are not monolithic, economic liberal ideas have penetrated deeply into aspects of governmental activity over the last thirty years. Even 'difference' has been harnessed to some extent to the justification of economic liberal models, through a conceptual transformation of demands from previously-excluded groups into elements within the diverse array of individualised customer needs that 
'new public management' can supposedly meet (for analyses see Clarke, 2004: 62-63, on 'desocialising difference'; Clarke and Newman, 1997; and Newman, 2000, especially p. 57). Marketised systems in principle can reduce effects from patterns of pre-assigned social status and negative categorisation of households (such as those occurring via perceived colour or impairment). Yet markets frequently rely on classifying risk across individuals, groups and places, while prior distributions of cultural and economic capital (plus varying household obligations, costs and commitments) remain crucial to the patterning of market-based opportunities. For housing, the private sectors sift and sort urban populations via the price mechanism, capacity to pay, and ascribed levels of risk, so that - when it comes to destinations in terms of neighbourhood and dwelling types - people are located in highly differentiated and unequal ways. Ethnicity is a potential factor here, but one among many.

Historically, risk evaluations and hierarchies of respectability to some extent passed across from private to public sector institutions, and this has been complemented by pressures from politics to mimic market features. Nonetheless, needs-led systems and equal opportunity requirements continue to generate divergence in duties of public/third sector bodies from those for private organisations. Alongside efforts to push market themes directly into welfare systems, however, have come numerous measures concerned with discipline, surveillance and control. Notable from the 1990s onwards in housing policy, these have deeper historical roots (see for example Tucker, 1966; Ward, 1974). Today, approaches revolve around efforts to contain 'deviance', minimise threats to property, divert 'unacceptable lifestyles', and enhance labour market disciplines, especially amongst people identified as dysfunctional or costly. The position should not be over-simplified, since the drive for social order reflects not only 'top-down' perceptions of requirements for containment, but also responses to fears and day-to-day indignities faced at grass roots. From an equalities perspective, practices need to be reviewed for differentiated effects across and within groups (Harrison and Sanders, 2006). Furthermore, amongst multiple political drivers for social order policies is concern about integration. Although the post-2001 community cohesion debate seemed to challenge multi-culturalism, ensuing strategies are also located to some extent within a framework of broader trends towards increased regulation of behaviours. As indicated above, ethnicity should not be perceived in isolation, and analysis may often need to prioritise other variables.

\section{Migration, tensions and social costs}

A decline in social services, educational opportunities, housing or income maintenance may heighten potential for tensions between groups, especially if labour market opportunities and conditions have deteriorated. A related scenario concerns immigration, and the proposition that acceptance and collaborative pathways become more elusive with a declining welfare system. Large-scale labour market in-migration differs in principle from arrival of people seeking asylum (despite overlaps), or arrivals via marriage. For destination countries, substantial labour market migrations fit well with economic liberal ideas on flexibility. They assist employers by depressing potential wage costs or health and safety constraints, may sometimes help avoid investment in training, and benefit private landlords and other entrepreneurs through increased demand. Working and living conditions are sometimes very poor, and it is no surprise 
that one Rowntree study found that one in five working immigrants 'reported hourly wages below £5' (JRF, 2007a). Tactics may conceivably include recruiting teams of employees from overseas deliberately to undermine UK conditions and wages agreements. Labour market in-migration, however, is legitimated politically far more blandly; by claims about improved growth, socio-economic reinvigoration, and specific labour shortages (as in care or health work), as well as supposedly general benefits of a 'free' labour market across the EU (or more widely).

In England, the biggest losers from arrival of workforces seem likely to be poorer groups amongst settled populations (white and BME), especially if they find reasonablypaid jobs more difficult to secure, but negative effects may also arise higher up employment hierarchies and across substantial sectors. For example, it seems there has already been deep erosion of the position of the 'indigenous' workforce in the UKbased merchant marine, in favour of lower-cost workers from elsewhere (see Crow in The Guardian, 3 April 2009). Given the limited rights of UK employees and trade unions, there are strong temptations for employers to bring outside labour onshore (for Lindsey refinery walkouts and Tesco, see The Guardian, 23 June; 27 June; 1 July; 2009). It is important to avoid participating in 'moral panics' about migrants, and myths need challenging (Finney and Simpson, 2009; also examples in Garner, 2009). Thus specific work on new migration, its geography, and neighbourhood change is invaluable (see Reeve, 2008). Yet, in more general terms, we should not deny that real material interests are at stake. Given the scale of recent in-migration, serious questions arise about social costs, especially for people at the bottom of the income slope in high impact areas. Numbers of Eastern European immigrants may have fallen substantially with the onset of recession (cf The Guardian, 21 May 2009), but effects in labour markets and neighbourhoods seem unlikely to disappear.

More caution is needed, furthermore, about where the moral high ground lies. While benefits of migration have been highlighted frequently, large population flows into labour markets in high-consumption economies ideally need appraising in terms of effects that population growth and increased consumption have on environments and global warming. Contemporary population movements are important elements in globalisation trends bound up with economic liberalism, unconstrained economic growth, and environmental over-exploitation. At the same time, labour market migration further complicates UK ethnic relations, in a period when welfare systems and job security have deteriorated. One official strategy could have been to police conditions and pay of migrant workers more effectively (not least given several scandals about their exploitation), and to ensure that services expanded before people arrived (and in as 'green' a manner as possible). UK governments are unlikely to offer substantial resources for such tasks. Furthermore, if there has been a genuinely severe labour shortage, government might have helped asylum-seekers integrate themselves more quickly and fully into education and employment, but it has often treated them as deviant outsiders.

One important potential focus for tensions is social rented housing, especially as this already has numerous other pressures. The sector is crucial for many low-income and vulnerable households, who may be 'economically inactive', facing inadequate, informal, intermittent or insecure jobs, or experiencing ill-health or impairments (for relevant material see Fletcher, 2008). Social renting and allied services have been subject to significant practices and interventions aimed at 'social engineering' or social 
control (mentioned above), perhaps increasing as the tenure has become more selectivist and (in places) stigmatised (cf Flint, 2006, for interventions across housing generally). There is a mix of support for the vulnerable with discipline and 'therapy', and interest in 'behavioural' panaceas has grown. There have also been themes (in debates) about imposing market-style incentives, reducing security and 'lifetime' possession, re-casting social tenure as a stage of transition, more "producer competition', and so forth. The large number of female-headed tenancies reflects the feminisation of relative poverty, along with housing difficulties linked to domestic and labour market trajectories. Yet this group has sometimes been a magnet for policy advocates seeking to 'contain', discipline, or deny need. National political discussions rarely emphasise the roles of social renting for disabled people, voices of tenants themselves, or the positive contributions and real lives of female heads of households.

Although established residents from various ethnic backgrounds and tenure situations may be hostile to newcomers nearby (or in areas that seem within reach), myths may develop and persist particularly around the supposed impact of new arrivals on social housing availability. (For examples of responses to the work of the EHRC on this issue, see The Independent, Post a Comment, http://www.independent.co.uk/news/uk/home-news/queue-jumping-immigrants-are-amyth; [July 2009]). Perceptions have been affected by the media treatment and presence of asylum seekers, as well as fears about EU migrant workers. Very recently the issue became significant enough to attract a government response, and changes to access rules for social renting may result ('Healey announces major plans for more homes and fairer lettings to meet local needs', 29 June, 2009, CLG; http://www.communities.gov.uk/news/housing/1268729 [9 July 2009]). The full effects of New Accession State labour market arrivals on social renting, however, will be delayed for some time, and impact is currently small nationally (Robinson, 2007). We do not know how many workers (or their families) will stay in Britain longer-term, or how many ex-council houses sold under the right-to-buy are being let to migrant workers, although there are already some housing effects via private landlords, together with implications for schools, GPs, and other services. This may be part of an emergent pattern of pressure on services, arising from rapid population growth alongside inadequate neighbourhood resources, and attracting media interest (see The Guardian, 20 April 2009).

Negative attitudes are encouraged through racist and nationalistic political and media discourses, and a material focus may give hostilities more force. Housing circumstances and fears provide one such foundation, even when the image of change is inaccurate or premature. Since so many people already have problems in accessing adequate services, schools, jobs and dwellings, newcomers may seem to increase pressures in many domains. Rowntree findings confirm that 'racial tensions' may be driven by struggles for resources such as employment and housing (JRF, 2007b), while work from Law et al., in an area of low-income social housing reveals that poverty, abandonment, disempowerment and associated 'shame, rage and anger' were 'often channelled into racist hostility and violence' (Law, et al., 2007). It is important to stress the differences from earlier post-war decades, both in the pace of migration and the weakened positions and options of many existing low-income groups. Furthermore, problems facing parts of the white working class in particular areas may have been exacerbated distinctively, by decline of their previous cultural as well as economic and political infrastructures and opportunities. We should be wary of over-generalising 
when considering working class households, or the diverse local narratives of urban decline and anxiety that may co-exist alongside more positive themes amongst residents. Watt (2006) offers illuminating comments on relevant issues here. At the same time, however, defensive outlooks may connect strongly to processes of social deprivation and insecurity, in economic and welfare conditions very different from those of the 1960s or 1970s (cf Watt, 2006: 1- 5, 13).

Perhaps there may have been tendencies amongst writers and advocates in ethnic relations towards implied denial over the experiences of some settled residents, and white working class people in particular, with prior assumptions that the latter misunderstand or misrepresent their own circumstances or interests. It seems to the present writer, furthermore, that the role of economic liberal strategies in migration developments may well be under-acknowledged within ethnic relations work. Maybe these suspicions are over-critical, but - given that many academics and some commentators from the political left bring high sensitivity to cultural or religious sensibilities when looking at BME groups (and also the possibility that this may inhibit criticism of practices; cf Gupta, 2009) - it is important to appraise 'indigenous' groups too 'from the grass-roots up'. Analysis needs to move beyond the importance (or otherwise) of 'whiteness' and its relationship with class (cf comments in Sveinsson, 2009), to address complexities of human agency, beliefs and interests more effectively. This does not mean accepting mythical accounts of change, but acknowledging real cleavages and pressures (within as well as between class categories, and certainly not solely around ethnicity), over cultural and material resources, traditions, practices, opportunities, and rights claims. At the end of the paper, we try to give this acknowledgement a practical connection, by exploring tentatively one set of options that might better insulate and protect some settled low-income and vulnerable households.

\section{Particularism and multi-culturalism}

Claims for particularism have grown, with assertions that UK service provision and public policies should more fully reflect particular preferences, cultural practices, and needs of identifiable groups and categories (for particularism see Spicker, 1993/94). This contrasts with struggles to establish universalistic systems of social rights and welfare, facilitating equality of access and treatment for individuals. The claims have relied to some extent on arguments that apparently-universalistic values needed reexamining in the light of multi-cultural awareness. Consequences of multi-cultural strands within public policies have included a heightened consciousness amongst groups of the capacity to make particularistic claims on the public domain, and some reduction in the focus on commonality of expectations. Meanwhile, research, practice and academic writing focussed around difference have increasingly shown sensitivity to cultural diversity. Going further, the repertoire came to include concepts such as 'coded racism', indicating that criticism of some BME cultures reflected underlying racist outlooks. Such an interpretation seems valid for specific moments, but if put more generally deserves caution. Hostilities to religions or cultural practices are by no means necessarily by-products of racisms, even though sometimes entwined with racist views.

The strengths of particularistic strategies in welfare systems lay especially in development of greater cultural awareness and competence in services, and 
encouragement of new 'voices' amongst service users. These benefits were evidenced, for example, through the UK's BME housing associations from the mid-1980s onwards (Harrison, 1995; Harrison, et al., 2005), and many examples of advantages of particularistic organisations can also be found across the disability movement. The problems of particularism relate in part to potential for privileging specific interests through public policies and resources. A strong defence was often available for this, however, when groups that benefited were amongst those previously excluded or denied adequate social services or accommodation. In the case of BME housing associations, groups previously with little power were able to participate in collective developments that created resources potentially controlled or managed on their behalf. Being subject to general rules for the sector, however, these associations were restricted from operating exclusively, while meeting identifiable (and widely shared) housing needs was at the heart of the programme.

One current general theme is that religious affiliation should be treated similarly to ethnic origin, gender, age or sexual orientation, as a basis for claims to various entitlements. There is no clear agreement around this in Britain, beyond the officially accepted need to prevent discrimination against people because of their faiths, in access to jobs and services. Certainly, it is not immediately clear that membership based on adherence to a belief system should give rise to exactly the same rights as any available in the case of group memberships arising from birth, accident, family, or biology. Neither is there any uncontested case for giving religious bodies a substantial say across public policy domains. Nonetheless, official engagement has developed fuller accommodation with diverse faiths (see especially DCSF, 2007; and interesting reports in PolicyWorld, Social Policy Association, Summer 2009: 22). There are many resource implications from accommodating cultural differentiation generally (as when catering for large numbers of languages), but difficult additional questions arise about how far and to whom a positive response on religion should extend. These are attracting renewed attention in light of government's recent legislative plans (see for instance Shepherd, 2009). The issues go beyond rights of individuals, touching on the goals of religious and cultural organisations, and the extent to which they can expect distinct places in law and policy. Rights claims clash, and many people may object if religious groups can avoid treating issues of sexual orientation, gender or discipline in ways that are demanded from secular bodies. Neither is it clear that 'respect' for religions should be protected by specific regulation, outside the widely-agreed necessity to suppress genuine incitements to hatred (where there is a case for considerably greater resources and effort).

The problems of bringing religious organisations into public policy can be highlighted by remembering that faith not only gives groups and individuals invaluable resources on which to draw in daily life, but also frequently implies that views (and behaviours) of others are wrong (or at least partly so). While certain religions (especially those historically less interested in conversion) may be relatively open to accepting a diversity of routes to enlightenment, others seek to shape policies and practices affecting people outside their own memberships. There are also issues of social control within groups not amenable to electoral processes, as faith-related organisations may cast assumed members of their communities in ways out of line with more general expectations about rights and equality (for claims about UK sharia courts, see The Guardian, 29 June 2009: 12). 
Extensive penetration of public policy domains by faith bodies can restrict opportunities and voices of those who do not 'believe', or believe differently. The example of religiously-led schools (and some faith-affiliated HE bodies) is especially salient here. Anxious to strengthen 'containment' of youth and family behaviours, and bring third sector actors and their resources into public services, government turned to particularist organisations as part of its armoury, while the multi-culturalist agenda helped provide legitimation. The character of ongoing debates on faith schools and related issues (including homophobia and the Academies programme) can be illustrated readily by consulting items on education from The Guardian (see endnote below). This could probably be replicated to some degree from other newspapers or websites. There seems to have been an extension of control by religious bodies or sponsors (especially Christian churches) within state-supported schooling, alongside implementation of a far from well-received Academies programme, while local democracy and parental participation have taken a back seat. Particular kinds of pupils and staff may be substantially disadvantaged through this shift.

This development would have been more difficult politically before the advent of multi-culturalism. Indeed, approving the first state funding for Muslim schools in 1998 - a step that redressed a longstanding disadvantage - paradoxically seems to have helped pave the way for the present shift of power (for reports on the approval, see The Guardian 10 and 12 January 1998 [including Hattersley]). While England's secularism facilitated the acceptance of multiculturalism, re-invigoration of faith interests in politics now threatens some of the achievements associated with that secularism. We should add that a secularist institutional approach is not comparable with a faith position, since the former need not as such imply any certainties about the human spirit or after-life, and may primarily concern the defining of boundaries for and in the public sphere. Indeed, some religious adherents themselves might favour such secularism as a mechanism to promote unity, freedom or protection for minorities. Increasingly, however, UK secularism has come under attack.

Of course, individuals have other facets to their roles and identities apart from religious affiliations. At the same time - when it comes to human agency - immense contributions are made by many people of faith at grass roots, when giving support unconditionally to vulnerable people. Such activities contrast markedly with the more judgemental and directive elements found under some religious banners, in the UK or overseas (see The Guardian, 26 June and 6 July 2009). Our focus, however, is on the growing power of religious organisations. In a recent paper, Flint cites scholarly writings on 'civilising offensives', whereby elites attempt 'projects of realigning the habits and cultural orientations of sections of their populations', and links this in an insightful way to the 'quest for community cohesion' (2009: 419). If I understand this theme correctly, the national engagement with faith communities discussed above would fit well the idea of a civilising offensive. It might even take us back towards the nineteenth century, when reclamation of the poor and the urban was a keen hope of religious campaigners, and attempts were made to handle 'welfare' through voluntary organisations and philanthropy rather than elected bodies. National strategies today may encompass efforts to require organisational commitment to concerns such as promoting cohesion, but core areas for institutional autonomy remain.

When it comes to housing, by contrast, religious and cultural issues as such seem unlikely to be especially problematic in the longer term. Local tensions arise over 
territory, social lives, and culture, sometimes indicated by conflicts between minorities as well as with the remaining white population. The varying nature of disputes has led to suggestions that, in a period of so-called 'super diversity', managing the interfaces is 'no longer a black $v$ white issue' (Beider, 2009). There are also continuing challenges about access to (and practices within) areas of ethnic clustering (including white clustering). The central housing difficulties, however, seem to be primarily about neighbourhood resources, maintaining the kind of secure environment that should be available everywhere (free of harassment and anti-social activities), and (crucially) choice, quality, cost and supply of appropriate dwellings. Indeed, we may find many areas of convergence across quite differing groups of households when it comes to practical housing aspirations (cf views reported in Phillips and Harrison, 2005), while some dwelling design and space improvements sought on cultural grounds may readily fit with what would be needed to improve accommodation for all households. This is not to say that culture is unproblematic, but to hypothesise that cultural or religious affiliations in themselves do not necessarily play very large roles in generating housing difficulties. Furthermore, governance of housing has to some extent regulated the entry of religion and culture into housing provision and access, and schemes in private and public sectors are not usually likely to be designated in religious terms.

\section{Localism, 'consumer insulation' and equal opportunities}

A manifestation of particularism not discussed so far is the idea that local people should collectively have some acquired rights over neighbourhoods, resources and services where they or their communities traditionally live. This claim arises politically in many countries, but in mainland Britain has probably been at its most overtly political in recent decades only at a small scale; as when campaigners in Wales challenged possession of homes in parts of their country by outsiders and English-speakers (in some cases burning dwellings). More conventionally, localised approaches to shared claims have been pursued in Britain through co-ops, via marketised solutions such as gated communities, in ideas for community land trusts, and within social housing. The latter has offered possibilities for varying levels of collective influence by tenants, with Scotland perhaps moving along a more interesting community-orientated route than England, but with the history of England's BME housing associations illustrating the attractions of securing ownership by community-focussed organisations, and of associated involvement in local labour strategies and 'value added' services (see Harrison, 1995).

Localised control of resources offers one of the few options to better entrench existing vulnerable groups, and to shelter households from dependence on market disasters and negative policy change, thereby achieving a measure of what can be referred to as consumer insulation. Institutional options could involve participation linked to genuine forms of asset-based welfare, with land and buildings treated as resources held in trust (inalienably perhaps), for tenants and potential tenants, and to assist wider local communities. While there might be flexibility - involving combinations of activities, tenures, dwellings and moves between them, and perhaps options for accumulating modest membership shares in equity - social housing would be recognised as a firm element in household pathways. At the centre of consumer insulation concepts lies a combination of collective and individual property rights. Such 
combinations form potential building blocks for a welfare and consumption system that might help confer security and sustainability, and perhaps provide bases for resistance to centralised power (cf Harrison, 1990). Standing firmly within longstanding traditions of constructing counter-models in marketised societies, collective options of this kind challenge economic liberalism, but also fit uneasily alongside strategies for individual formal rights to equal treatment. Indeed, concepts about protecting individual equality rights (and the 'free competition' to which they contribute) have served sometimes to help undermine the legality of localism in varied forms, including local labour recruitment.

Earlier UK analysts were alarmed by local policy ideas such as those favouring 'sons and daughters' as applicants for dwellings in council estates, and local rights of use and control over dwellings or services might imply citizenship becoming more fragmented by accumulations of entitlements. Yet, in a period when circumstances look much less optimistic, low-income settled residents rarely have extensive formal means for pursuing their property aspirations, or protecting any claims they may feel to local rights of residence, autonomy, jobs, health services, schools or anything else. This contrasts sharply with many better-off households, who can access a variety of resources. Given adequate frameworks of rules, enhancing local collective control of property might be one way forward for tenants, and might lead to 'greener' living if it encouraged local sourcing of goods and labour while making capital less footloose. It might even help people put pressure on central government to confront more of the costs that accompany unplanned immigration, and to expand services and social housing investment, rather than leaving low-income groups (BME and white) to cope with increased pressures.

Perhaps there is a policy paradox here. For while some types of particularistic claims to collective recognition have become more accepted in politics in England, others remain neglected; notably those rooted not in faith or difference but in place, history and ongoing deprivation. There have been recognitions from time-to-time of local needs or connections in homelessness policies and housing allocation (and local priority is being revisited by government), but approaches have usually looked more like rationing practices than shifts of power. Yet fuller recognition of local claims from those who feel dispossessed could raise hard questions about newcomers and further differentiation. Indeed, such recognition would challenge the 'moral landscape' reformers have become accustomed to when discussing equal opportunities, migration and difference. Beyond this lies a further possibility. Given the political challenges posed by localism and grass-roots sectional interests to economic liberal ways, perhaps entrenchment of a formal equal opportunities agenda may in the longer term prove more of an advantage than a threat to the legitimation and maintenance of marketised systems. For the present writer, it would be disappointing if equality rules proved to be key weapons for defence of the 'free' labour market, movement of capital, and provider competition. At present I am unsure about the viability of such a hypothesis, but mention it to re-emphasise the need to look afresh at assumptions we have become acclimatised to. 


\section{Acknowledgements}

The paper draws on an April 2009 presentation for a Glasgow seminar convened by the University of Manchester's Institute for Political and Economic Governance in association with the UK's Equality and Human Rights Commission (EHRC). Thanks are due to participants for criticisms, to Nigel Sprigings for encouraging an ideas piece, and to PPP for helpful referee comments.

\section{Notes}

Education-related items consulted from The Guardian include those on 13 June 2006; 3 April 2007; 3 July 2007; 10 September 2007; 20 November 2007; 24 November 2007; 4 December 2007; 27 March 2008 [letters]; 13 May 2008; 2 September 2008; 3 September 2008 [letters]; 9 September 2008; 16 September 2008; 20 December 2008; 6 January 2009; 13 January 2009 [letters]; 20 January 2009; 10 March 2009; 5 May 2009; and 29 June 2009.

* Correspondence Address: Malcolm Harrison, School of Sociology and Social Policy, University of Leeds, LS2 9JT. Email: m.I.harrison@leeds.ac.uk.

\section{References}

Beider, H. (2009) The potential of housing organisations' role in tackling diversity and cohesion challenges. Paper at Seminar on Housing, sustainable communities and good relations, $8^{\text {th }}$ April, Manchester.

Clarke, J. (2004) Changing welfare changing states: new directions in social policy. London: Sage.

Clarke, J. and Newman, J. (1997) The managerial state. London: Sage.

Department for Children, Schools and Families (DCSF) (2007) Faith in the system: The role of schools with a religious character in English education and society. Nottingham: DCSF Publications.

Equality Challenge Unit (ECU) (2007) Conducting Equality Impact Assessments in Higher Education. London: ECU.

Finney, N. and Simpson, L. (2009) 'Sleepwalking to segregation?': Challenging myths about race and migration. Bristol: The Policy Press.

Fitzpatrick, S. (2005) Poverty of place - Working Paper. York: University of York, Centre for Housing Policy.

Fletcher, D.R. (2008) Employment and disconnection: cultures of worklessness in neighbourhoods, in: J. Flint and D. Robinson (eds) Community cohesion in crisis? Bristol: The Policy Press, pp. 99-117.

Flint, J. (2006) Active, responsible citizens? Changing neighbourhoods, changing order, in: A. Dearling, T. Newburn and P. Somerville (eds), Supporting safer communities: housing, crime and neighbourhoods. Coventry: $\mathrm{ClH}$, pp. 29-44.

Flint, J. (2009) Cultures, ghettos and camps: sites of exception and antagonism in the city. Housing Studies, 24, 4, 417-431. 
Flint, J. and Robinson, D. (eds) (2008) Community cohesion in crisis? Bristol: The Policy Press.

Garner, S. (2009) Home truths: the white working class and the racialization of social housing, in: K. Sveinsson (ed) Who cares about the white working class? London: Runnymede Trust, pp. 45-50.

Gupta, R. (2009) Response. We don't need Hegel. The burka is a cloth soaked in blood. The Guardian, $8^{\text {th }}$ July, p. 29.

Harrison, M. (1990) Welfare state struggles, consumption, and the politics of rights. Capital and Class, 42, Winter, 107-130.

Harrison, M. (1995) Housing, 'race', social policy and empowerment. Aldershot: Avebury.

Harrison, M. (2009) UK Migrant and minority ethnic groups: housing experiences, policy responses and the research agenda, in: A. Vitorino, Migrations: opportunity or threat? Housing and health in the integration of immigrants: recommendations of the 2008 Gulbenkian Migrations Forum. Cascais, Portugal: Principia, Fundacao Calouste Gulbenkian.

Harrison, M. with Davis, C. (2001) Housing, social policy and difference: disability, ethnicity, gender and housing. Bristol: Policy Press.

Harrison, M., Phillips, D., Chahal, K., Hunt, L. and Perry, J. (2005) Housing, 'race' and community cohesion. Coventry: $\mathrm{ClH}$.

Harrison, M., Law, I. and Phillips, D. (2005) Migrants, minorities and housing: exclusion, discrimination and anti-discrimination in 15 member states of the European Union. Vienna: European Monitoring Centre on Racism and Xenophobia.

Harrison, M. and Sanders, T. (2006) Vulnerable people and the development of 'regulatory therapy', in: A. Dearling, T. Newburn and P. Somerville (eds), Supporting safer communities: housing, crime and neighbourhoods. Coventry: $\mathrm{ClH}, \mathrm{pp} .155-168$.

Joseph Rowntree Foundation (2007a) East European immigration and community cohesion. Findings. York: JRF.

Joseph Rowntree Foundation (2007b) Social cohesion in diverse communities. Findings. York: JRF.

Law, I. (2007) Housing choice and racist hostility: Better Housing Briefing 4. London: Race Equality Foundation.

Law, I., Hemmerman, L., Sirriyeh, A. and Simms, J. (2007) Racist hostility and racist victimisation. Research Findings. University of Leeds: CERS.

Markkanen, S. (2009) Looking to the future: changing black and minority ethnic housing needs and aspirations: Better Housing Briefing 11. London: Race Equality Foundation.

Minton, A. (2007) Changing places. Search, Winter, 7-9.

National Audit Office (2008) Widening Participation in higher education. Report by Comptroller and Auditor General. HC Session 725, 2007-2008.

Newman, J. (2000) Beyond the new public management? Modernizing public services, in: J. Clarke, S. Gewirtz, and E. McLaughlin (eds) New managerialism, new welfare? London: Sage, pp. 45-51.

Phillips, D. and Harrison, M. (2005) Perspectives from the grass roots: a Bradford case study and its implications, in: M. Harrison, D. Phillips, K. Chahal, L. Hunt, and J. Perry, Housing, 'race' and community cohesion. Coventry: $\mathrm{ClH}$, pp. 170-201. 
Reeve, K. (2008) New immigration and neighbourhood change, in: J. Flint and D. Robinson (eds) Community cohesion in crisis? Bristol: The Policy Press, pp. 177197.

Robinson, D. (2007) European Union Accession State migrants in social housing in England. People, Place \& Policy Online, 1, 3, 98-111.

Shepherd, J. (2009) Student life: one long holiday? Education Guardian, 5th May, p. 8.

Spicker, P. (1993/1994) Understanding particularism. Critical Social Policy, 39, 13, 3, Winter, 5-20.

Sveinsson, K. (2009) The white working class and multiculturalism: is there space for a progressive agenda? in: K. Sveinsson, (ed) Who cares about the white working class ? London: Runnymede Trust, pp. 3-6.

Toynbee, P. (2009) This bold equality push is just what we needed. Comment and Debate. In 1997. The Guardian, $28^{\text {th }}$ April, p.31.

Tucker, J. (1966) Honourable Estates. London: Victor Gollancz.

Ward, C. (1974) Tenants Take Over. London: The Architectural Press.

Watt, P. (2006) Respectability, roughness and 'race': neighbourhood place images and the making of working-class social distinctions in London. International Journal of Urban and Regional Research, 30, 4, 776-797. 